\title{
"A CIDADE TAL COMO ELA É VISTA POR SEUS HABITANTES": NOVA YORK COMO ESPAÇO DE MEMÓRIA NO OLHAR DE WILL EISNER
}

\author{
Marcos Paulo Torres Pereira* \\ Marcelo Lachat**
}

\begin{abstract}
Resumo: Este estudo objetiva compreender como o espaço urbano da cidade de Nova York, na narrativa de Will Eisner, torna-se matéria de fabulação em constructos narrativos que evocam uma entidade de urbe, matizada pela soma de representações simbólicas que lhe são ulteriores, gerando mecanismos coletivos de identificação e pertencimento, no ato de rememorar e na articulação de signos na conjugação de subjetivismos e coletividade.
\end{abstract}

Palavras-chave: Memória. Cidade. Afetos. Símbolo. Trauma.

"E quantas casas e ruas são necessárias para que uma cidade comece a ser uma cidade?"

Wittgenstein

O título deste estudo é uma citação a Will Eisner, que na introdução de Nova York: a vida na grande cidade, obra composta de quatro romances gráficos distintos (Nova York: a grande cidade, O edifício, Caderno de tipos urbanos e Pessoas invisiveis) produzidos por Eisner entre 1981 e 1992, explica que errônea é a compreensão das grandes cidades como acúmulos de edifícios, grandes populações e grandes áreas, aludindo à imagem real destas os olhares de seus residentes, que a vivenciam e que a reconhecem: "O real é a cidade tal como ela é vista por seus habitantes. O verdadeiro retrato está nas frestas do chão e em torno dos menores pedaços da arquitetura, onde se faz a vida do dia-a-dia” (EISNER, 2009, p. 19).

Tomando suas palavras como ponto de partida, enveredaremos pela cidade de Nova York tendo lugares de memória como cicerones, a fim de compreender como esse espaço urbano, espaço de memória, torna-se matéria de efabulação em constructos narrativos que evocam uma entidade de urbe, no ato de rememorar e na articulação de signos na conjugação de subjetivismos e coletividade. Ressaltamos que não é a Nova York real que visitaremos, mas o constructo representativo erigido pelo autor, produto de impressões e memórias, que resgata e ressignifica na formação da cidade os anos do pós-guerra, em aproximações e distanciamentos do indivíduo e da coletividade.

Partiremos com a seguinte acepção na bagagem: a cidade não se perfaz apenas no resultado da soma de lugares privados e públicos (que, por sua natureza, evocam a

\footnotetext{
* Doutorando em Teoria e História Literária na Universidade Estadual de Campinas. Professor assistente de literaturas de língua portuguesa na Universidade Federal do Amapá. E-mail: marcospaulo@unifap.br.

** Doutor em Letras (Literatura Portuguesa) pela Universidade de São Paulo. Pós-doutorando no Programa de Pós-Graduação em Letras da Universidade Federal de São Paulo. Professor adjunto de literaturas de língua portuguesa na Universidade Federal do Amapá. E-mail: marlachat@hotmail.com.
} 
condição humana de pluralidade), mas na soma de representações simbólicas que lhe são ulteriores, gerando mecanismos coletivos de identificação e pertencimento. A cidade, como espaço, como lugar, além de elemento agregador, é portadora de entidade.

O lugar, segundo Milton Santos (SANTOS, 1994, p. 36), é a extensão do acontecer solidário, inter-relações de se viver junto, do coletivo. Essas inter-relações, por sua natureza, geram manifestações simbólicas do espaço numa memória compartilhada, numa memória solidária que, por extensão, passa a ser a memória citadina. Memória da cidade é memória da urbe e de tudo aquilo que à urbe é relacionada.

"Uma memória que se recorda dos locais (...) aponta para a possibilidade de que os locais possam tornar-se sujeitos, portadores de recordação e possivelmente dotados de uma memória que ultrapassa amplamente a memória dos seres humanos" (ASSMANN, 2011, p. 317). O rememorar em Nova York... não é linear, não é um mapa em que os caminhos estão pontilhados até que se encontre o " $x$ " como marcação espacial, é fragmentado, por vezes até disperso, sem que haja uma personagem ou fato que permaneça do início ao fim do relato, entretanto personagens que surgem e desaparecem, como fogo fátuo, como memórias moventes, que antecipam um devir memória que potencializa a entidade citadina. $\mathrm{O}$ que o leitor encontrará serão lugares de memórias demarcados pelo autor que despertam a memória da cidade e o reconhecimento da entidade da urbe.

Nesse romance o autor resgata testemunho dos fatos, tornando explícitas as espécies de reação e/ou adaptação das personas ao ambiente da cidade, que lhes imprime uma circunstância de tempo e espaço e que as condiciona à incorporação na urbe, da mesma maneira que as afasta do outro. A cidade rememorada é um organismo que não suscita, e sim exige organicidade. Na introdução ao Caderno de Tipos Urbanos, um dos romances gráficos que compõem Nova York..., Eisner assevera:

\footnotetext{
Viver numa cidade grande pode ser comparado a existir numa selva. Tornamo-nos criaturas do ambiente. A reação aos ritmos e coreografias é visceral, e em pouco tempo a conduta de um morador fica tão singular quanto a de um habitante da selva. Vemos habilidades ancestrais de sobrevivência e mudanças sutis de personalidade afetarem o comportamento. Aqui temos uma espécie de estudo arqueológico de tipos urbanos. Para mim, os tipos urbanos sempre parecem singulares em seu estilo e sensibilidades. É claro, a vida nas entranhas de uma grande cidade é muito diferente daquela de uma pequena comunidade rural. Conforme acumulam-se a astucia das ruas e as habilidades de sobrevivência, afirma-se o triunfo do meio ambiente sobre todos nós.

Os principais fatores ambientais que caracterizam a cidade são: tempo, cheiro, ritmo e espaço. O tempo da cidade tem uma cadência especial. É afetado pela breve duração dos eventos. O cheiro é uma cacofonia de emissões de um sem-número de empreendimentos. O ritmo é um elemento da velocidade que dita como os habitantes têm de negociar o movimento. E o espaço é a limitada área habitável deixada pelos obstáculos no labirinto de concreto (EISNER, 2009, p. 238-240).
}

Os lugares que compõem a urbe, em suas inter-relações, no discurso se tornam lugares de memória por adquirem o papel de dispositivos de constituição de subjetividades, em pulsões, pois para a memória a significação do ocorrido matiza-se em experiências pessoais do indivíduo, fazendo com que esses se identifiquem com os espaços eleitos, unifiquem-se e se reconheçam como agentes de seu tempo. 
A concepção de experiência é, quiçá, centralidade nos escritos de Walter Benjamin, que desde Experiência e pobreza (1986) evoca a necessidade de vinculação desta ao indivíduo, asseverando que o excesso de informações advindos da modernidade acaba por gerar um aniquilamento de experiências. Miríades de informações advêm ao indivíduo, porém elas se tornam inóxias se não lhes são significativas. Benjamin postula, então, um novo conceito de barbárie, com base na carência de experiências do mundo moderno: a escassez de uma e o excesso da outra (informações) impelem indivíduos a "partir para frente", a um recomeço, a um vivenciar para a construção de um novo mundo, ou seja, a dotação de significados a símbolos.

Dar significado a um símbolo, sob os moldes avocados por Benjamin, é humanizar o simbólico. Assim, Eisner, morador da grande cidade, reconhece os tipos que o cerca, os lugares, imagens e cheiros, reverberando histórias colhidas nas estranhas de Nova York que transformam indivíduos em tipos urbanos. Não se espere na obra alusões a cartões postais, porque a cidade que encontraremos é a dos habitantes, e não a dos turistas... É a cidade daqueles que possuem a potência de reconhecê-la pelo devir memória, e não daqueles que a vêem pela primeira vez ou que simplesmente dela se informam.

"O tempo torna-se tempo humano na medida em que está articulado de modo narrativo; em compensação, a narrativa é significativa na medida em que esboça os traços da experiência temporal" (RICOEUR, 1994, p. 15). As palavras de Ricouer vêm ao encontro das de Benjamin, a partir de um diálogo cujo tema seja temporalidade e experiência. Nesses termos, constituída em várias temporalidades, a entidade de Nova York é forjada pelos relatos de Eisner mediante registro de um denso acúmulo de memórias, pois que muitas são as personagens que as resgatam, inter-relacionando símbolos e significações oriundos de lugares de memória, revivificando relatos que narram experiências orbitais a lugares de memória, como satélites de corpos celestes, da entidade citadina que, nesta metáfora, lhes seria o sistema solar. Pesavento, ancora-se nos escritos de Paulo Ricouer para uma leitura de cidade marcada pela unicidade espaçotemporal:

\begin{abstract}
Lidando com as duas dimensões, do espaço e do tempo, da arquitetura e da narratividade, Paul Ricoeur (1998) nos mostra o princípio através do qual ambas trocam sinais e se relacionam: o espaço se dá a ler, o tempo se dá a ver, com o que retomamos a idéia do cronotopo e a uma postura hermenêutica que se dispõe a decifrar sentidos, sobretudo aqueles que nos chegam do passado. Esta seria, portanto, uma tarefa a ser levada em conta por uma história cultural do urbano: partindo do entendimento antropológico da cultura como um conjunto de sentidos partilhados, o historiador buscaria resgatar a alteridade do passado de uma cidade através das representações de tempo e espaço que ela oferece. Ou, em outras palavras, trataria de abordar a cidade através de um olhar que a contemplasse como uma temporalidade que encontra forma e sentido no espaço, ou como um espaço que abriga múltiplas temporalidades e sentidos (PESAVENTO, 2005, p. 9-10).
\end{abstract}

O que foi recolhido pelo rememorar se torna matéria literária, através de pulsão de ficção, mediante a necessidade de ressignificar lugares de memória. $\mathrm{O}$ autor, inebriado pela aura da cidade, tece narrativas em que entidades (não somente das personagens, mas da própria cidade) são envolvidas, misturadas, até que se tornem uma. 
A cidade gera interações de subjetividades individuais e referências coletivas, sem esquecer, contudo, da materialidade que desperta dimensão simbólica. Assim, o olhar de Eisner escaneia a cidade de Nova York, guiado por elementos plurais que, no instante ressignificado pela memória, perdem sua funcionalidade, sua existência primária como objeto da urbe, tornando-se sujeito da ação guia do rememorar: lugar de memória.

Nova York... fia-se como um devir memória, por não se concentrar numa postura simplesmente nostálgica, cujos fatos se concentrariam em derredor de Eisner, numa função memorialista redutora, e sim na memória do lugar, constituinte da entidade da urbe num fluxo permanente, num movimento ininterrupto de depuração de narrativas à caracterização citadina. Assim, como a lente de uma polaróide que captura o instante que, depois de fotografado, será constituinte da aura simbólica evocada pelos lugares de memória dessa urbe, Eisner, em tom confessional, explica-nos a necessidade de relato:

\begin{abstract}
Nascido e criado na cidade de Nova York, e tendo sobrevivido e crescido lá, eu carrego comigo uma carga de lembranças, algumas dolorosas e outras alegres, que ficaram trancadas no cárcere da minha mente. Tenho essa necessidade de um velho marinheiro em compartilhar meu acervo de experiência e observações. Se quiser, pode me chamar de uma testemunha gráfica registrando a vida, a morte, o sofrimento e a luta incessante para triunfar... ou, pelo menos, sobreviver (EISNER, 2007, p. 7).
\end{abstract}

As memórias ficam trancadas, até que gatilhos sensoriais as disparam para que sejam rememoradas. $\mathrm{O}$ que aqui chamamos de gatilhos se refere àquilo que se torna capaz de gerar reconhecimento e reavivamento, indo além das marcações geográficas (pois que a elas não estão tão somente presas) e espaciais (à proporção que resgata noções do vivido e já distanciado, em diálogo com o presente, ora sentido). Lugares de memória corporificam tessituras, construções e estruturas simbólicas vivificadas em matéria para a re-elaboração de conceitos ressignificados numa linguagem própria de cidade. Sua linguagem é simbólica porque a memória interpõe significados às partes que integram a cidade, gerando significantes de urbe, tornando possível uma ordenação ideológica.

A cidade, como símbolo, torna-se estabilizadora de rememorações, desenvolvendo sua linguagem através de dois constructos para os quais orbitam os sentidos: o primeiro, de caráter físico, é aquele que o visitante conhece, percebendo os aspectos múltiplos e universais comuns a todas as grandes cidades; o segundo, de caráter identitário, é a cidade dos habitantes, dos tipos urbanos, referente aos elementos caracterizadores particulares somente àquela urbe.

O habitante é dotado de um mapa mental que a linguagem da cidade possibilita interpretar, um guia de percursos a serem seguidos para que se assuma a entidade de tipo urbano e da própria urbanidade. Eisner apresenta àqueles que não habitam a grande cidade, aos visitantes, narrativas plurais (como múltiplas são as constituições de urbe), fragmentos de vivências como micronarrativas que compõem a macronarrativa da cidade, buscando que seu leitor possa assimilar tal mapa mental dos habitantes.

A primeira de suas agregações de micronarrativas de Nova York... intitula-se " $O$ tesouro da avenida " C", cujo lugar de memória, a "marcação cardeal" (para permanecer na metáfora do mapa mental), é um respiradouro do metrô que passa sob essa avenida. À primeira vista, esse seria apenas o espaço no qual as personagens praticariam suas ações, 
entretanto, intercalando fatos, além de uma vinheta de abertura e outra de fechamento na qual esse respirador é central, o espaço deixa de ser cenário para tornar-se partícipe da narrativa e lugar de memória à entidade de urbe.

O texto que se apresenta na primeira vinheta denuncia esta entidade, ao fazer referência às "colisões no fluxo da vida": "Então veio o metrô e os seus respiradouros, com grelhas salpicando a superfície de frestas encardidas, filtrando os dejetos e os inevitáveis destroços de incontáveis destroços de incontáveis colisões no fluxo da vida, para lá ficarem por incontáveis anos à espera dos caçadores de tesouro" (EISNER, 2009, p. 21).

São cinco atos que compõem o drama de $O$ tesouro da avenida " $C$ ": "O anel”, "O dinheiro", "A arma", "A chave" e "O tesouro". Como evocação à brevidade e ao recorte de vida observado, os títulos de cada uma se estruturam apenas por um substantivo, acompanhado de artigos que os definem (não é qualquer anel, mas aquele que sinalizou à quebra de esperanças na realização amorosa de Henry e Mary, personagens do primeiro ato; não é qualquer chave, mas aquela que acena para o fim do caso amoroso entre as personagens do quarto ato). Objetos ordinários que passam a ser o cerne sob o qual as ações orbitam, que têm em comum o mesmo destino, o substrato de memórias colhidas pela cidade no respiradouro do metrô (os objetos caem no respiradouro por motivos distintos, mas o fim é o mesmo).

Entre "A arma" e "A chave" há uma vinheta de duas páginas que apresenta previamente as personagens do quinto ato, "O tesouro". O último ato retrata a busca dessas personagens pelo tesouro da cidade, os objetos apresentados anteriormente. As personagens são duas crianças que, após recolherem tais objetos, brigam pela partição do butim. Aceitam dividir o dinheiro igualmente entre eles, um ficaria com o anel e a chave e outro com a faca, porém o segundo garoto recusa essa partição, pois anel e chave não teriam valor. Durante a briga, chave, anel e faca caem novamente no respiradouro. Os garotos contentam-se com o dinheiro, pois o valor material era o que lhes interessava, contudo ao leitor dá-se uma sensação de perda, pois a esses foram apresentados afetos e traumas que agregam valor aos objetos perdidos, tornando-os bens simbólicos. A última vinheta aumenta essa carga emotiva, ao mostrar esses objetos abandonados que antes tiveram tanta importância a outrem.

O choque é palpável: objetos que servem de gatilhos de rememoração, elementos à compreensão e à entrada na cidade, lugares de memória para se assimilar a visão da urbe das memórias de Eisner, são fadadas ao abandono e ao esquecimento, como que anunciando aos leitores visitantes a não importância dos indivíduos e sim a participação deles na composição da entidade da urbe. Os elementos não importam, podem ser esquecidos ou substituídos, mas o todo orgânico, a grande cidade, como resultado de somatórios de entidades, é o que importa.

A urbe, assim, é um lócus, um espaço marcado no tempo (um entrelugar que abarca d'O anel a $\mathrm{O}$ tesouro) num devir memória que possui a possibilidade de absorção das micronarrativas como representações dos tipos urbanos que vivenciaram os atos. Entretanto, por sua força, seguindo os postulados de Eckert e Rocha (2005, p. 161) acerca das relações entre tempo e cidade, é responsável pela dissolução dos signos culturais que demarcam as personagens, transformando as micronarrativas em pré-textos para que se 
narre nova história na qual a cidade é a centralidade. $O$ autor se vê na necessidade de narrar dado devir memória, ficcionalizando seu rememorar em aspectos humanos universais, comuns a pessoas de todas as épocas, culturas e grupos sociais, que serão filtrados pela entidade citadina, até que a grande cidade surja como substrato.

São marcadores de rememoração em Nova York: a grande cidade: O tesouro da avenida “C”, Degraus, Metrôs, Lixo, Música de rua, Sentinelas, Janelas, Paredes e O quarteirão. Há aqui o uso de maiúsculas por estes serem os títulos das agregações de micronarrativas que compõem a macro. Em outras palavras, a grande cidade é devir memória nestas histórias agregadas que, por sua vez, são lugares de memória para as narrativas que agregam. Em Sentinelas, por exemplo, o devir memória realiza-se por intermédio das transfigurações cambiantes entre o comum e o simbólico, figurando encontros e desencontros entre o passado e o presente, nos seguintes objetos que abandonam sua condição ordinária e se tornam lugares de memória: hidrante, meio-fio, manancial, alarme de incêndio, caixa de correio, carta morta, correio de última hora, semáforo, poste de iluminação, esconde-esconde, esgotos e o rio.

"Esgotos" é apenas uma vinheta de uma página, composta por quatro tiras, mas talvez uma das mais significativas se analisada tendo a entidade de urbe como fina lupa: a primeira tira mostra um fluxo de água dirigindo-se a boca de um esgoto. As três tiras seguintes servem como um zoom de câmera, aproximando ao leitor os dejetos que essa água transporta, para, na quarta tira, focalizar-se em uma folha, rasgada e encharcada, com a seguinte mensagem:

\footnotetext{
Querido Charles,

Sei que você compreenderá quando eu lhe disser que vou me casar no próximo domingo. Espero que você não fique muito magoado, tendo em vista o nosso relacionamento nos últimos meses. Há muito tempo já sei que aquilo que existe entre nós é apenas físico e que não poderia durar mesmo (EISNER, 2009, p. 101).
}

Na última tira, a mensagem está caindo no esgoto, não se podendo presumir se há outras folhas que já foram tragadas ou se ali naquela página terminava a missiva. Não obstante, não há necessidade desta ciência, pois o que se mostra é suficiente para revelar a brutalidade com a qual os afetos são apagados na urbe. Apesar de ter se dado um relacionamento amoroso entre a emissora e Charles, não houve espaços para nada romântico, tampouco nada suavemente amoroso. Para a emissora fora algo simplesmente carnal, no pragmatismo de se saciar um desejo. Para Charles, muito menos se deu amor, pois que este tipo de missiva seria guardado como instrumento de rememoração por aquele que quisesse manter vivo o que findara. $\mathrm{O}$ esgoto se transforma em metáfora não somente de esquecimento, mas de abandono a quaisquer desejos ou possibilidades de memória. O terceiro envolvido nesta micronarrativa, o leitor, não tem elementos suficientes para conhecer as personagens, mas percebe a entidade citadina de forma acachapante sobre o devir memória entre o esquecimento e a negação do rememorar. "Diferente do dever de memória - que para preservá-la a pensa como inteira - o devir memória sabe que ela já é ausência, esquecimento, por isso aposta no presente, no processo de rememoração como um ato de sempre tornar-se" (VEIGA, 2015, p. 95). 
No romance gráfico $O$ edifício, Eisner segue com um modelo de narrativa orbital. Enquanto em Nova York: a grande cidade tínhamos uma série de micronarrativas circundando lugares de memória, neste temos apenas quatro narrativas, agora mais extensas, sobre quatro fantasmas que ficam em derredor ao edifício que nomeia a obra. As quatro histórias têm em comum a ação de estabilizadores de memória, a afetividade, o símbolo e o trauma.

Apesar de longa, citamos na íntegra a introdução da obra pela importância que esta terá a nossos argumentos:

\begin{abstract}
Após muitos anos vivendo numa cidade grande, desenvolvendo gradualmente uma sensação de assombro - é tanta coisa que acontece por lá sem explicação, como que por mágica.

Enquanto eu crescia em meio à turbulência da vida urbana, bastava apenas um sentido superficial de alerta para lidar com o rebuliço de transformações e experiências que passavam correndo por nós. Havia pouco tempo para refletir a respeito da rápida substituição das pessoas e dos prédios. Eu dava estas coisas como certas.

Conforme envelheci e acumulei recordações, passei a sentir com maior intensidade o desaparecimento de pessoas e referências. Para mim era especialmente inquietante a insensível remoção de edifícios. Eu sentia que, de alguma maneira, eles tinham um tipo de alma. [grifo nosso]

Agora sei que estas estruturas, incrustadas de riso e manchadas de lágrimas, são mais do que edificações sem vida. Não é possível que, tendo feito parte da vida, eles não absorvam de alguma forma a radiação proveniente da interação humana.

E imagino o que resta quando um edifício é demolido (Eisner, 2009, p. 159-160).
\end{abstract}

Halbawachs (apud ASSMANN, 2011, p. 273) afirma: "Toda personalidade e todo fato histórico, já por ocasião de sua entrada na memória social, é transposto a uma doutrina, a um conceito, a um símbolo; nessa ocasião já se lhe atribui um sentido e se o transforma em um elemento do sistema de ideias da sociedade". A cidade, repetimos, é responsável pela constituição de uma memória socialmente mediada e compartilhada. Nestes termos, determinadas partes integrantes da cidade acabam por herdarem um dístico em relação a outros elementos mediante agregação de valor e/ou referência que os habitantes da urbe escolheram, de forma consciente (mediante uma campanha para este fim, por exemplo) ou inconsciente (através de representações caras à comunidade que acabam por se espalhar pelo restante da cidade) apregoar. Seja como for, isso só se pode realizar pela ação de uma negociação entre o individual e o coletivo naquilo que Eisner descreveu como "radiação proveniente da interação humana" e que aqui adotamos na acepção de entidade.

\footnotetext{
Por mais de oitenta anos o edifício fincou-se no cruzamento de duas grandes avenidas. Era um marco cujas paredes resistiam à chuva de lágrimas e ao golpe de risadas.

Com o tempo, um acúmulo invisível de dramas formou-se ao redor de sua base.

Um dia o prédio foi demolido, deixando em seu lugar um horrível vazio e o resíduo de destroços psíquicos.

Depois de vários meses, um novo edifício ergueu-se de dentro da cratera.

Hoje... Em algum momento durante a manhã, aparecem na entrada quatro fantas: Monroe Mensh, Gilda Green, Antonio Tonatti, P.J. Hammond (EISNER, 2009, p. 161-164).
} 
Eisner confessa que os edifícios que eram removidos da cidade para ele, de alguma maneira, tinham um tipo de alma. Isso se deu por seu reconhecimento de que tais elementos serviam como marcadores de rememoração por meio de uma simbolização sob os quais recaia agregação de sentido. Eisner era um daqueles tipos urbanos que referenciamos anteriormente neste estudo, porquanto não é de todo impossível crer que outros que vivenciaram experiências congêneres as do autor também atribuíssem a esses ditos edifícios marcadores de sentido iguais ou aproximados ao que ele atribuía.

Quatro desses tipos humanos, se ficcionalizados não fossem, seriam Monroe Mensh, Gilda Green, Antonio Tonatti e P. J. Hammond, aludidos nas primeiras páginas do romance. Mas, como ficcionalizados são, na obra eles também adquirem o caráter de estabilizadores de memória, assim como o edifício, seja por afeto, seja por trauma. Em comum, tiveram sua vivência demarcada pelo edifício. Na morte, como fantasmas, como entidades, tornaram-se contexto, pois suas histórias se somaram a história do prédio, gerando-lhe valor simbólico, tornando-o símbolo. Individualmente, cada um se prende ao plano físico pelo afeto ou pelo trauma, pelo "golpe de risadas" ou pela "chuva de lágrimas". A ficionalização destes tipos urbanos, tivessem ou não existido, não é obstáculo para que a memória evoque a entidade da urbe, ao contrário, possibilita a apreensão de outros caracteres desta.

\begin{abstract}
Assim, ao reler as quatro graphic novels originais que compõem este livro (...) fiquei surpreso com a brutalidade de tantas histórias - tão brutais, tão indiferentes quanto uma cidade. Duas trabalhadoras têxtis e um bebê morrem num incêndio; um hidrante que é a única fonte de água de uma imigrante é fechado; uma senhora é assaltada diante de testemunhas que nada fazem além de zombar dela; a vida de um homem é destruída por causa de um erro de digitação do jornal. É verdade, há sentimento aqui, pois o sentimento faz parte do ser humano, e seria tolo o observador da humanidade que deixasse isso de fora (Dickens certamente não o fez), e Eisner era de fato um observador notável, mas há pouco sentimentalismo nessas páginas (GAIMAN, 2009, p.07).
\end{abstract}

Assmann, acerca da simbolização, escreve:

[...] seria prematuro descrever essa recordação tornada símbolo como ficção e mentira, apenas porque ela declaradamente nada tem a ver com a verdade histórica. Não se deve subestimar a importância dessas recordações formuladas (...). Essa reinterpretação, que (...) não se deve equiparar necessariamente com falsificação, dá uma contribuição importante para a estabilização das recordações no desenvolvimento de uma entidade pessoal (ASSMANN, 2011, p. 275).

Só se fica guardado aquilo que é importante ao coração, sejam golpes de risadas ou chuvas de lágrimas. $\mathrm{O}$ contexto no qual se inserem as memórias possibilita um acesso mais profícuo a estas, dada a potência de manipulação de memória que o contexto exerce no desenvolvimento das narrativas, na atribuição significativa e na corporificação da entidade. Entretanto, a forma como essas contextualizações agem na narrativa não é igual.

Afeto e trauma são marcadores de rememoração, requerem um contexto para que se lhe atribua capital simbólico, entretanto são totalmente antagônicas entre si. Enquanto a recordação pelo afeto propicia alento, a que se dá pelo trauma propicia corrosão, 
enquanto o afeto serve como instrumento de definição de si, o trauma não é assimilável na estrutura identitária.

O trauma é uma dor contínua que causa uma impossibilidade de movência. A memória do trauma é retomada da impossibilidade de movência, como ferida que não cessa de doer, como corrosão de si. "Embora uma parte inalienável do homem, o trauma não é assimilável na estrutura identitária da pessoa, é um corpo estranho que estoura as categorias da lógica tradicional: ao mesmo tempo interna e externamente, presente e ausente" (ASSMANN, 2011, p. 279).

A narração de traumas é um trabalho de tratamento da dor, quando a linguagem é burilada de forma a se atingir uma catarse: "ante o trauma, a linguagem comporta-se de forma ambivalente. Há a palavra mágica, estética, terapêutica, que é efetiva e vital porque bane o terror, e há a palavra pálida, generalizadora e trivial, que é a casca oca do terror" (ASSMANN, 2011, p. 278). Narrativas que evocam o terror do trauma renunciam às chagas com as quais a rememoração corrói o ente. Sobre o tema, vaticina Bernardo Lewgoy:

\begin{abstract}
Enquanto o trauma remeteria para a compulsão de repetição de uma lembrança congelada como eterno presente - sendo, nesse sentido, inarticulável como experiência narrativa transmissível em sua completude - a narrativa remete para o trabalho de luto que, ao separar passado e presente, permite à vítima da violência elaborar, simbolizar e narrar o seu sofrimento, violência e perdas, libertando-se do peso da lembrança e habilitando o sujeito para a continuação de uma vida normal (LEWGOY, 2010, p. 53).
\end{abstract}

O primeiro dos fantasmas narrados é Monroe Mensh, descrito como um filho da cidade que cresceu no anonimato por sua habilidade de manter-se à parte, dominando a arte de cuidar, apenas, da própria vida. O que poderia parecer índice de solidão ou de misantropia era, antes, uma forma de se manter na organicidade da urbe, um modo de se manter partícipe da entidade maior. Essa escolha de vida funcionou para ele até o dia em que houve um atentado na frente do edifício: um carro passou metralhando contra os pedestres. Monroe não se mexeu e uma bala ricocheteou próxima a ele e atingiu uma criança.

A imovência em agir custara a vida da criança e Monroe tinha ciência disso. Esse é o momento que o traumatizará durante toda a história. Ele se nega a continuar com seu emprego, a seguir na escolha de vida que fizera, buscando salvar pelo menos uma criança, como forma de pagar um débito que estipulara para si. Entretanto, por conscientemente ter escolhido não fazer parte da vida, mantendo-se a distância do outro, a personagem se vê inapta à quitação, tudo que fazia para esse fim falhava, mas, mesmo ante as falhas, negava-se a ficar em débito.

Anos passaram até que um dia presencia o atropelamento de uma criança. Ele segue a ambulância que a socorre ao hospital. A criança precisava de sangue para uma operação de emergência, porém seu tipo sanguíneo era raro. Para efeito narrativo, era o mesmo tipo de sangue de Monroe. A criança não sobrevive pela gravidade dos ferimentos; Monroe também não, por ter tido uma embolia enquanto doava sangue para tentar salvar o infante. Pela última vez, ele falha. 
Gilda Green, outro dos fantasmas, em vida fora estrela da escola e poderia ter casado com qualquer um dos melhores partidos do bairro. Mas ao invés disso, apaixonase pelo poeta da turma. A escola acaba e, para surpresa de todos, o namoro continua. Ela começa a trabalhar como auxiliar de dentista, ele passava os dias na biblioteca produzindo suas poesias à espera de uma publicação. Encontravam-se todos os dias na porta do edifício. Gilda um dia decide que o relacionamento não tem futuro e avisa que vai se casar com o dentista. O amor de Gilda pelo poeta é maior e continuam como amantes, encontrando-se todos os dias na hora do almoço no mesmo lugar. Os anos passam. $\mathrm{O}$ marido de Gilda descobre o caso e nada faz. Gilda vai se desculpar com ele e descobre que o marido também tinha um caso. Gilda e o marido calam e não tomam nenhuma atitude de rompimento, ao contrário, no decorrer da narrativa há um momento em que o marido diz para deixar as coisas como estavam.

Mais anos passam até que Gilda adoece e morre. O poeta continuou indo todos os dias para o edifício, mesmo sua amada estando morta. O que faz com que o poeta vá todos os dias para a frente do edifício era o hábito e a memória de Gilda, matizada pelo afeto. O que fez com que Gilda se encontrasse todos os dias com o poeta era o amor que sentia. Seu fantasma permaneceu porque era lembrança de afeto.

Assim como a rememoração motivada pelo afeto é diferente daquela motivada pelo trauma, afeto e símbolo também são. Assmann define:

O que é afeto para as recordações da juventude é o símbolo para as recordações da velhice. Afeto e símbolo são estabilizadores de espécies bem diferentes. A recordação que ganha a força de símbolo é compreendida pelo trabalho interpretativo retrospectivo em face da própria história de vida e situado no contexto de uma configuração de sentido particular (ASSMANN, 2011, p. 271).

Em $O$ edificio, afeto, símbolo e trauma estabilizam recordações ao mesmo tempo que constituem uma significação de vida citadina, mesclando-se nos "resíduos de destroços psíquicos", incrustando o simbólico de riso e manchas de lágrimas. O que causa o contexto, ou a agregação de valor simbólico às vivências, é o mesmo valor que é substrato das negociações entre o indivíduo e a comunidade, porém o que marca a permanência das personagens como fantasmas é uma tentativa de revolta contra a delimitação destes como tipos urbanos, em busca de uma realização como indivíduo. A urbe venceria o indivíduo, por isso morreriam sem realizações.

Acontece que a história não estava ainda findada e um momento de clímax faz com que as histórias de cada um dos quatro fantasmas, que até então em comum tinham apenas o cenário do edifício, se coadunem, misturem-se em prol do objetivo que lhes era comum: realizarem-se. Um lavador de janelas cai do edifício e é salvo pelos quatro fantasmas, cada um participando da ação com o melhor que tiveram em vida. O salvamento acontece, realizam-se como indivíduos e podem descansar em paz.

A impressão é que o indivíduo vencera a entidade da urbe, porém a realização destes só se deu mediante agrupamento e negociação entre indivíduo e coletivo. A urbe oportunizou-lhes o realizar, contanto que se assumissem na organicidade desta, contanto que se assumissem como tipos urbanos. A entidade da urbe se faz sentir mais uma vez, 
por ser ela a responsável por permitir e oportunizar que marcadores de recordação (edifício $=$ símbolo, Gilda Green = afeto, Monroe Mensh = trauma) se complementassem para lhe caracterizar.

O espaço urbano é lugar de intercâmbio material e simbólico do habitante da cidade, porquanto gatilho para a rememoração. Para Aleida Assmann (2011, p. 91), “'O passado recordado' não é para ser confundido com o conhecimento geral desinteressado do passado que denominamos "história". Ele sempre está relacionado com os projetos identitários, com as interpretações do presente e as pretensões de validade". Palavras que se adéquam em perfeição à análise das polaróides de vida que o romance gráfico de Eisner produz, porque, dada o intercâmbio de representações, tais polaróides validam lugares de memória como entes significantes de carga simbólica pelo reconhecimento e pela assimilação da concepção da entidade de urbe, substrato das inter-relações entre indivíduos e espaço, indivíduos e coletividade.

\section{REFERÊNCIAS}

ASSMANN, Aleida. Espaços da recordação: formas e transformações da memória cultural. Trad. Paulo Soethe (coord.). Campinas: Ed. da Unicamp, 2011.

BENJAMIN, Walter. Experiência e pobreza. In: BOLLE, Willi (Org.). Documentos de cultura, documentos de barbárie. São Paulo: Cultrix / Edusp, 1986.

ECKERT, C.; ROCHA, A. L. C. da. O tempo e a cidade. Porto Alegre: Ed. da UFRGS, 2005.

EISNER, Will. Um Contrato com Deus e Outras Histórias. São Paulo: Devir Livraria. 2007.

Nova York: a vida na grande cidade. São Paulo: Companhia das Letras, 2009.

GAIMAN, Neil. Uma Introdução. In: EISNER, Will. Nova York: a vida na grande cidade. São Paulo: Companhia das Letras, 2009.

LEWGOY, Bernardo. Holocausto, trauma e memória. In: Web Mosaica - revista do Instituto Cultural Judaico Marc Chagall. v.2 n.1 (jan-jun), 2010, p. 50-56.

PESAVENTO, Sandra Jatahy. Cidade, espaço e tempo: reflexões sobre a memória e o patrimônio urbano. In.: Cadernos do Lepaarq. Vol. II, nº 4, Pelotas: UFPel, 2005.

RICOEUR, Paul. Tempo e narrativa. vol. I. Campinas: Papirus, 1994.

VEIGA, Roberta. Já visto jamais visto: um filme de filmes ou o devir memória. In: Crítica Cultural Critic, Palhoça, SC, v. 10, n. 1, p. 87-96, jan./jun. 2015. ISSN 1980-6493.

\section{Recebido em 02/02/2016. Aprovado em 04/03/2016.}

Title: "The city how is seen by its inhabitants": New York as a space of memory in Will Eisner's eye

Abstract: This study aims to understand how the New York's urban space, in Will Eisner's narrative, becomes matter of fabulation in narrative constructs that evoke a metropolis entity, nuanced by the sum of symbolic representations that are subsequent to him, generating collective mechanisms of identification and belonging, in the act of remembering and in the articulation of signs in the conjugation of subjectivism and collectivity.

Keywords: Memory. City. Affection. Symbol. Trauma.

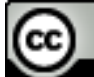

Este texto está licenciado com uma Licença Creative Commons Atribuição 4.0 Internacional. 